\title{
Deformidad ósea de radio derecho
}

\author{
Right radius bone deformity
}

Presentamos el caso de una mujer de 65 años que fue remitida a la Consulta de Reumatología por deformidad del antebrazo derecho de larga evolución. La paciente no tenía ningún antecedente de interés y en la anamnesis por aparatos sólo refería un encorvamiento progresivo del antebrazo derecho, sin traumatismo previo. En la exploración física sólo destacaba incurvación de radio derecho (figura 1). En la analítica destacaba fosfatasa alcalina (FA) 202 U/L (valores normales 40-125 U/L), siendo la gamma glutamil transpeptidasa, la bilirrubina y las transaminasas normales. Se realizó radiografía de antebrazo derecho en la que se objetivó deformidad marcada de la mitad distal, pérdida de diferenciación entre la cortical y la medular, y áreas mixtas de esclerosis y radiotransparencia (figura 2A). Se realizó gammagrafía ósea con tecnecio 99 marcado con bisfosfonatos (BSFs) en la que se mostró captación en radio derecho (figura $2 \mathrm{~B}$ ). La paciente fue diagnosticada de diagnosticada de Enfermedad Ósea de Paget (EOP) y, a pesar de la elevación de FA, no se pautó tratamiento con BSFs basándonos en los resultados del estudio PRISM ${ }^{3}$.

La EOP es un trastorno esquelético crónico y focal, siendo actualmente la enfermedad metabólica ósea más frecuente tras la osteoporosis. Suele diagnosticarse por encima de los 60 años y predomina ligeramente en varones. Las causas no son bien conocidas y actualmente se considera una enfermedad multifactorial con participación de factores ambientales y genéticos. ${ }^{1}$ La principal alteración se encuentra en los osteoclastos, que aumentan en número, tamaño y actividad, produciendo un remodelado óseo acelerado que da lugar a un hueso inmanuro y desorganizado, muy vascularizado y menos compacto, con tendencia a la deformación 0 a la fractura. Aunque en la mayoría de las ocasiones es una enfermedad asintomática, puede producir dolor, deformidad, calor local, fracturas, artropatía por vecindad y neuropatías por compresión, entre otros. El diagnóstico se basa en la clínica, la elevación de marcadores de remodelado óseo y la radiología. El tratamiento de elección son los BSFs. ${ }^{2}$ La EOP puede afectar a un solo hueso (enfermedad monostótica) 0 a varios huesos no contiguos (enfermedad poliostótica), siendo la afectación del hueso del radio muy rara (1,5\%). ${ }^{4}$ Hay que realizar el diagnóstico diferencial con procesos oncohematológicos (mieloma, metástasis óseas condensantes) o distrofias y displasias óseas (displasia fibrosa, osteopetrosis, picnodisostosis, osteítis condensante del ilíaco, osteodistrofia renal). Es necesario pensar en esta enfermedad en pacientes mayores de 60 años con deformidad en cualquier área del esqueleto, no siendo indicación de tratamiento la elevación de FA en pacientes asintomáticos.

\section{Bibliografía}

1. del Pino Montes J, Corral Gudino L, Sánchez MD, Calero I, Carranco TE, Quesada Moreno A. Enfermedad ósea de Paget, osteomalacia y sarcopenia. Medicine. 2014;11(60):3555-66.

2. Vallet M, Ralston SH. Biology and Treatment of Paget's Disease of Bone. J Cell Biochem. 2016;117(2):289-99.

3. Langston AL, Campbell MK. Fraser WD, MacLennan GS, Selby PL, Ralston SH; PRISM Trial Group. Randomized trial of intensive bisphosphonate treatment versus symptomatic management in Paget's disease of bone. J Bone Miner Res. 2010 Jan;25(1):20-31. doi: 10. 1359/jbmr. 090709.

4. M. Gumà, Rotés D, Holgado S, Monfort J, Olivé A, Carbonell J, Tena X. Enfermedad ósea de Paget: estudio de 314 pacientes. Med Clin (Barc). 2002:119(14): 537-540.
Figura 1. Deformidad de radio derecho, convexidad dorsal

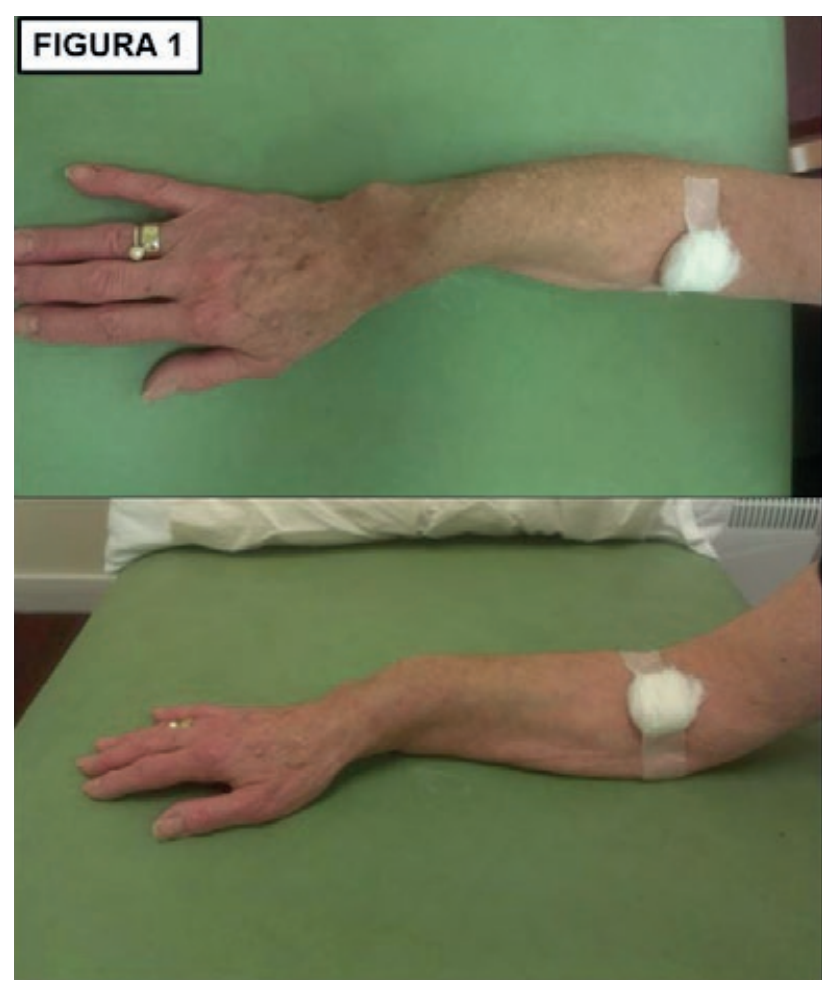

Figura 2. 2A: Radiografía anteroposterior y lateral de antebrazo derecho. Deformidad, pérdida de diferenciación entre la cortical y la medular, áreas mixtas de esclerosis y radiotransparencia. 2B: Gammagrafía con Tecnecio 99 marcado con BSFs. Aumento de actividad en radio derecho

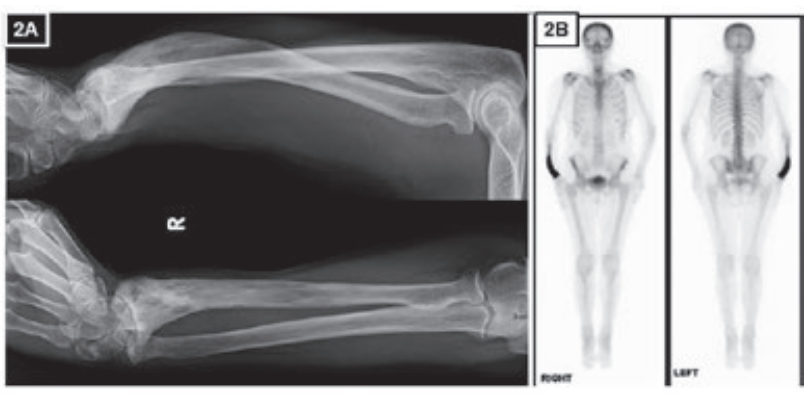

\section{Diagnóstico}

\section{Enfermedad Ósea de Paget del radio}

Ismael Calero Paniagua', Ricardo Usatequi Martín²
'Servicio de Medicina Interna. Hospital General Virgen de la Luz. Cuenca. España.
'Departamento de Medicina. Universidad de Salamanca. Salamanca. España.

Correspondencia: ismaelcaleropaniagua@yahoo.es

Como citar este artículo: Calero Paniagua I, Usatequi Martín R.

Deformidad ósea de radio derecho. Galicia Clin 2016; 77 (4): 190

Recibido: 07/03/16 ; Aceptado: 28/04/16 